Case Report

\title{
An Isolated Phlebolith on the Lip: An Unusual Case and Review of the Literature
}

\author{
Gabriela de Morais Gouvêa Lima, Renata Mendonça Moraes, \\ Ana Sueli Rodrigues Cavalcante, Yasmin Rodarte Carvalho, and Ana Lia Anbinder
}

\begin{abstract}
Department of Bioscience and Oral Diagnosis, Institute of Science and Technology, Campus São José dos Campos, Univ. Estadual Paulista (UNESP), Engenheiro Francisco José Longo Avenida 777, 12245-000 São José dos Campos, SP, Brazil
\end{abstract}

Correspondence should be addressed to Ana Lia Anbinder; ana.anbinder@ict.unesp.br

Received 6 April 2015; Accepted 8 July 2015

Academic Editor: Hiroko Kuwabara

Copyright (C) 2015 Gabriela de Morais Gouvêa Lima et al. This is an open access article distributed under the Creative Commons Attribution License, which permits unrestricted use, distribution, and reproduction in any medium, provided the original work is properly cited.

Background. Calcified thrombi are a common finding, especially in the pelvic veins. There are generally multiple thrombi, and they are generally associated with vascular malformations. Design. Herein we report a rare case of a single labial phlebolith, not associated with any other vascular lesion. We aim to alert clinicians to the possibility of the occurrence of vascular thrombi in the mouth and to describe the clinical and histological characteristics of such lesions in order to simplify the diagnosis and treatment. Furthermore, we have reviewed the English-language literature published since 1970 reporting oral (including masticatory muscles) phleboliths. Results. Twenty-nine cases of phleboliths have been reported in the literature since 1970. Only three of the reported phleboliths were solitary and not associated with other vascular lesions, as in the case presented here. Conclusion. Although phleboliths not associated with other vascular lesions are not common, clinicians should be aware of the existence of this pathology and include it as differential diagnosis of oral lesions.

\section{Introduction}

Phleboliths are calcified thrombi usually associated with other vascular lesions, as vascular malformations (VM), and are caused by blood stasis [1] or even trauma [2].

In the literature, they are commonly found on routine radiographs of cases diagnosed as VM or hemangiomas, although they are better detected by computerized tomography $[1,3,4]$. Radiographically, they present as oval structures with concentric radiolucent or radio-opaque laminations. They can be found in periapical regions near dental structures in a plain radiograph $[5,6]$. Nonionizing techniques, such as magnetic resonance imaging and ultrasound, can provide good images demonstrating the location and extent of the lesions $[6,7]$.

The pelvic area is the most common area affected by phleboliths, which can occur within prostatic, uterine, or intestine veins. Phleboliths are not unusual in the head and neck, but there are few cases in the literature of phleboliths not associated with other vascular anomalies [8-10]. When a phlebolith is located in salivary gland regions, it can be clinically misdiagnosed as a sialolith or salivary gland disease, especially when there is intermittent swelling, despite not being associated with food intake. In these cases, sialography can be used as diagnostic tool [11-13].

Besides imaging exams, biopsy followed by microscopic examination can help in the final diagnosis. Histologically, a phlebolith is seen as concentric calcifications with an onion-like appearance inside a vessel, caused by repetitive mineral deposition on a thrombus and secondary lamellar fibrosis $[2,7,13]$. Commonly, hematoxylin and eosin (HE) and immunohistochemistry are used $[10,14,15]$, but use of electron microscopy and X-ray microdiffraction has also been reported [14].

We report herein an unusual case of a phlebolith presenting as a single lesion, not associated with a VM and clinically misdiagnosed as a neurofibroma. In describing this case, we aim to help clinicians to deal with this uncommon but simple lesion. We have also reviewed the literature of oral/masticatory muscle phleboliths. 


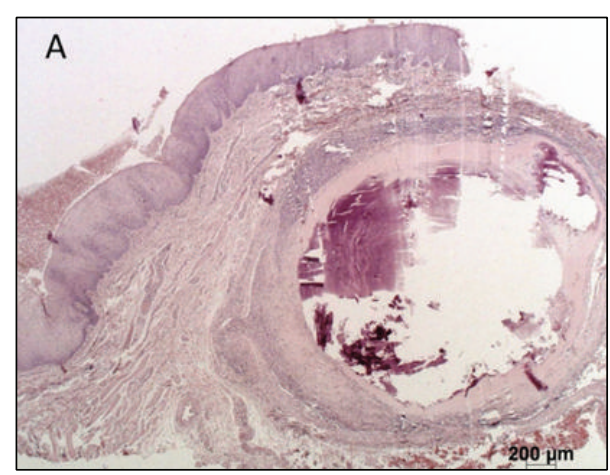

(a)

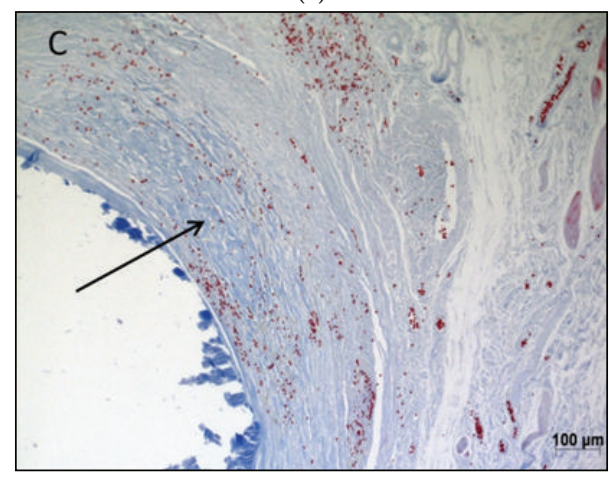

(c)



(b)

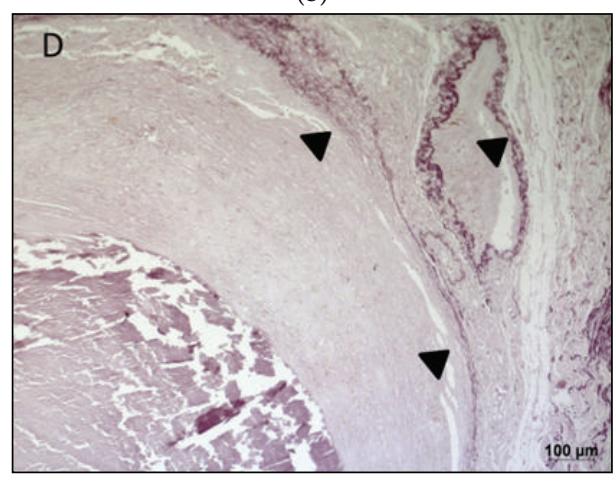

(d)

Figure 1: Microscopic aspect of the lesion showing the vascular structures ((a) and (b) hematoxylin and eosin stain), collagen (Masson's Trichrome (c)), and elastic fibers (Weigert stain (d)).

\section{Report of Case}

A 56-year-old woman was referred to our institution presenting with a white-yellow painless papule in the right labial commissure. It was approximately $3 \mathrm{~mm}$ in diameter and firm to palpation and had been growing slowly for approximately one year, following trauma. The patient reported swelling after trauma with subsequent diminution and then a recent increase in volume. Her previous medical history was unremarkable.

No radiograph was performed, and the clinical diagnostic hypothesis was neurofibroma and pleomorphic adenoma. An excisional biopsy was performed followed by histopathological examination.

Microscopic examination revealed a submucous dilated vessel filled by a calcified thrombus with a concentric pattern of mineralization and surrounded by granulation tissue and small capillaries under a hyaline layer. The covering mucosa was intact and presented no alterations (Figure 1).

The diagnosis of phlebolith was confirmed by histochemical Weigert's and Masson's Trichrome staining and by immunohistochemistry with anti-CD34 and anti-smooth muscle actin (SMA) (Table 1; Figure 2), as evidenced by the vascular endothelium (CD34-positive), smooth muscle wall (SMA-positive), tunica intima elastic fibers (Weigert's elastic stain), and surrounding collagen fibers (Masson's Trichrome) of the vessel filled with the calcified thrombus.
TABLE 1: Antibodies and protocol used for immunohistochemistry.

\begin{tabular}{lcc}
\hline Antibody & Antigen retrieval & Concentration \\
\hline SMA (Dako) & No retrieval & $1: 100$ \\
CD34 (Dako) & $\begin{array}{c}\text { Dako Target Retrieval } \\
\text { Solution, pH 9 }\end{array}$ & $1: 100$ \\
\hline
\end{tabular}

Complementary electron microscopy with energy dispersive X-ray spectrometry (EDS) revealed the presence of calcium $(\mathrm{Ca})$, carbon $(\mathrm{C})$, silicon $(\mathrm{Si})$, and magnesium $(\mathrm{Mg})$ (Figure 3), compatible with a phlebolith. The patient was followed without any complication after surgery.

\section{Review of the Literature}

Medline and Web of Science databases were searched using the descriptors "oral phlebolith" and "phleboliths," "phlebolith," "oral thrombus [case report]," and "lip and thrombus." Table 2 shows all cases of phleboliths in the oral region (including masticatory muscles) reported in the English literature from 1970 to 2013.

We found 29 cases of phleboliths. In five cases, there were multiple phleboliths not associated with other vascular lesions (16.13\%), and, in four cases (12.90\%), there was a solitary phlebolith, but only one was associated with a lesion diagnosed as hemangioma. Only three reported phleboliths 


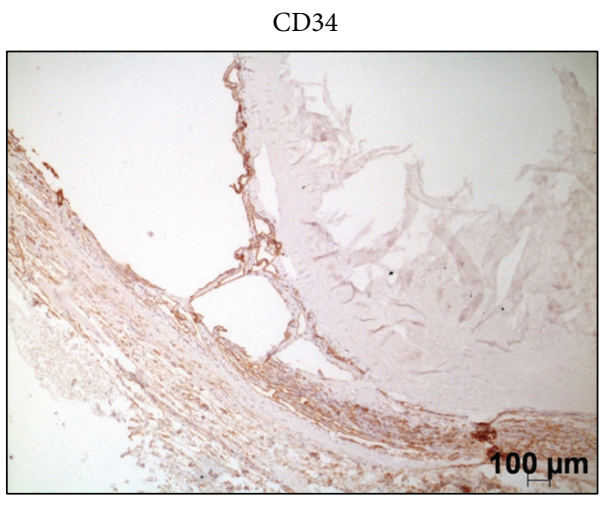

(a)

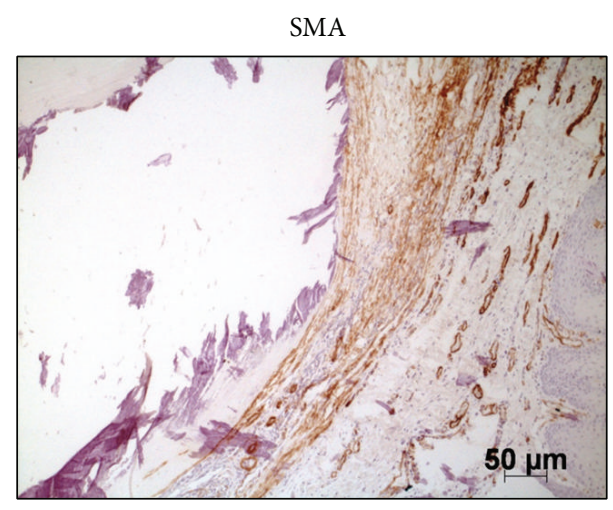

(b)

FIGURE 2: Immunohistochemistry showing vascular endothelium stained with anti-CD34 (a) and smooth muscle wall stained with anti-SMA (b).

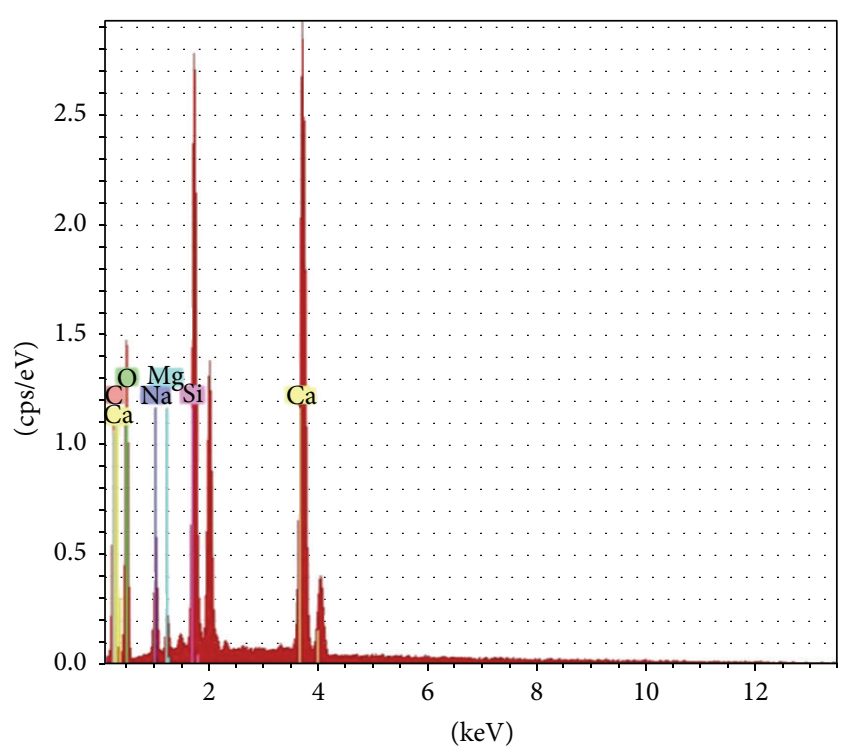

FIGURE 3: Energy dispersive X-ray spectrometry (EDS), results in graphic, with peaks of calcium, carbon, silicon, and magnesium.

were solitary and not associated with other vascular lesions, as in the case presented here.

Based on the reviewed literature, phleboliths of the oral region can be found in infants to elderly individuals, but mainly between the first and third decades of life (55.2\%), with no sex predilection ( $48.28 \%$ female: $51.72 \%$ male), and are sometimes associated with masticatory muscles (27.6\%).

\section{Discussion}

Phleboliths are calcified thrombi that commonly appear as multiple calcifications related to lesions diagnosed as VM or hemangiomas $[1-4,6,7,11-21]$. They are rarely reported as solitary calcifications and/or not associated with a vascular lesion [8-10], as in the case reported here. We have reported herein a case of a single phlebolith on the lip, probably caused by trauma. The clinical appearance of a white-yellow color papule, without a calcified aspect or consistency, led us to suspect a neurofibroma or a small salivary gland lesion; therefore, we did not radiograph the lesion, which could have helped us with an accurate diagnosis.

The diagnosis of a phlebolith is commonly made by physical and imaging examinations and confirmed by microscopy (HE stain). In some cases, immunohistochemistry or even electron microscopy $[10,14,15]$ is used. In our case, we reached the final diagnosis only after biopsy, and it was confirmed by histochemistry (Weigert's elastic stain and Masson's Trichrome), immunohistochemistry (CD34 and SMA), and EDS.

The EDS showed peaks of C, Ca (interpreted as calcium carbonate), $\mathrm{Mg}$, and $\mathrm{Si}$. A study of arterial biomineralization in autopsies found both apatitic and nonapatitic calcifications in different zones of the arterial wall [22]. The literature shows that the calcified crystals are mainly composed of phosphate and calcium carbonate, components of apatite. Minor crystals of $\mathrm{Mg}$ can be present in the hydroxyapatite [11, 17], and even Si may be present. Studies have shown that $\mathrm{Si}$ is a component of biomineralization [22], which was recently described as being involved in the early stages of this process [23]. The mineral composition, though phosphorus was missing, is intriguing; however, the components that should be present in a phlebolith are not well established, and the area we analyzed using EDS may not have been a representative area of apatitic calcification.

Cases of phleboliths not associated with other vascular lesions are rarely reported in the literature, especially as solitary nodules [8-10]. Trauma may have caused the slow flow, thrombus development, and consequent mineral deposition in this case.

\section{Conclusion}

Despite the rarity of this condition, clinicians should be aware of the existence of single phleboliths not associated with other vascular lesions when facing a submucous lesion on the lip or 
TABLE 2: Cases of phleboliths in the oral region (including masticatory muscles) reported in the English literature from 1970 to 2013.

\begin{tabular}{|c|c|c|c|c|c|c|}
\hline Author & Year & Location & Multiple & Other vascular lesions & Sex & Age \\
\hline O’Riordan [11] & 1974 & Lower lip/neck & Yes & Yes & Female & 23 \\
\hline O’Riordan [11] & 1974 & Buccal soft tissue & Yes & Yes & Male & 43 \\
\hline O’Riordan [11] & 1974 & Mandible & Yes & Yes & Female & 27 \\
\hline O’Riordan [11] & 1974 & Buccal soft tissue & Yes & Yes & Female & 47 \\
\hline Keathley et al. [12] & 1983 & Submandibular & Yes & Yes & Male & 23 \\
\hline Ikegami and Nishijima [16] & 1984 & Buccal soft tissue & Yes & Yes & Male & 23 \\
\hline Gunge et al. [14] & 1987 & Buccinator muscle & Yes & Yes & Female & 41 \\
\hline Sano et al. [17] & 1988 & Buccal soft tissue & Yes & Yes & Male & 17 \\
\hline Sano et al. [17] & 1988 & Buccal soft tissue & Yes & Yes & Female & 37 \\
\hline Hupp [18] & 1989 & Maxilla & Yes & Yes & Male & 20 \\
\hline Zachariades et al. [8] & 1991 & Masseteric muscle & Yes & No & Male & 8 \\
\hline Zachariades et al. [8] & 1991 & Masseteric muscle & Yes & No & Female & 9 \\
\hline Zachariades et al. [8] & 1991 & Maxillary antrum & No & No & Male & 42 \\
\hline Kurita et al. [9] & 1994 & Tongue & No & No & Female & 69 \\
\hline Scolozzi et al. [13] & 2003 & Retromolar region & Yes & Yes & Female & 92 \\
\hline Çankaya et al. [19] & 2003 & Submental & Yes & Yes & Male & 18 \\
\hline Chuang et al. [3] & 2005 & Submandibular & Yes & Yes & Male & 65 \\
\hline Altuğ et al. [1] & 2007 & Masseteric muscle & No & Yes & Male & 21 \\
\hline Altuğ et al. [1] & 2007 & Buccal soft tissue & Yes & Yes & Male & 22 \\
\hline Altuğ et al. [1] & 2007 & Submental/submandibular/neck & Yes & Yes & Male & 21 \\
\hline Kanaya et al. [7] & 2008 & Masseteric muscle & Yes & Yes & Female & 14 \\
\hline Su et al. [20] & 2009 & Submandibular & Yes & Yes & Female & 26 \\
\hline Mandel and Perrino [2] & 2010 & Buccinator/masseter & Yes & Yes & Female & 56 \\
\hline Mandel and Perrino [2] & 2010 & Tongue & Yes & Yes & Female & 64 \\
\hline Gharaibeh et al. [15] & 2010 & Floor of the mouth & Yes & Yes & Male & 11 \\
\hline Orhan et al. [4] & 2012 & Lower and upper lip/buccal soft tissue & Yes & Yes & Male & 20 \\
\hline Kato et al. [10] & 2012 & Buccal soft tissue & No & No & Female & 17 \\
\hline Zengin et al. [6] & 2013 & Masseteric muscle & Yes & Yes & Female & 21 \\
\hline
\end{tabular}

other regions susceptible to trauma and should include them in the differential diagnosis.

\section{Conflict of Interests}

The authors declare that there is no conflict of interests regarding the publication of this paper.

\section{References}

[1] H. A. Altuğ, V. Büyüksoy, K. M. Okçu, and N. Doğan, "Hemangiomas of the head and neck with phleboliths: clinical features, diagnostic imaging, and treatment of 3 cases," Oral Surgery, Oral Medicine, Oral Pathology, Oral Radiology and Endodontology, vol. 103, no. 3, pp. e60-e64, 2007.

[2] L. Mandel and M. A. Perrino, "Phleboliths and the vascular maxillofacial lesion," Journal of Oral and Maxillofacial Surgery, vol. 68 , no. 8, pp. 1973-1976, 2010.

[3] C.-C. Chuang, H.-C. Lin, and C.-W. Huang, "Submandibular cavernous hemangiomas with multiple phleboliths masquerading as sialolithiasis," Journal of the Chinese Medical Association, vol. 68, no. 9, pp. 441-443, 2005.

[4] K. Orhan, M. Icen, S. Aksoy, H. Avsever, and G. Akcicek, "Large arteriovenous malformation of the oromaxillofacial region with multiple phleboliths," Oral Surgery, Oral Medicine, Oral Pathology and Oral Radiology, vol. 114, no. 4, pp. el47-e158, 2012.

[5] L. A. Parker Jr. and H. H. Frommer, "Phleboliths. Report of a case," Oral Surgery, Oral Medicine, Oral Pathology, vol. 18, no. 4, pp. 476-480, 1964.

[6] A. Z. Zengin, P. Celenk, and A. P. Sumer, "Intramuscular hemangioma presenting with multiple phleboliths: a case report," Oral Surgery, Oral Medicine, Oral Pathology and Oral Radiology, vol. 115, no. 1, pp. e32-e36, 2013.

[7] H. Kanaya, Y. Saito, N. Gama, W. Konno, H. Hirabayashi, and S.-I. Haruna, "Intramuscular hemangioma of masseter muscle with prominent formation of phleboliths: a case report," Auris Nasus Larynx, vol. 35, no. 4, pp. 587-591, 2008.

[8] N. Zachariades, G. Rallis, J. Papademetriou, E. Konsolaki, S. Markaki, and M. Mezitis, "Phleboliths. A report of three unusual cases," British Journal of Oral and Maxillofacial Surgery, vol. 29, no. 2, pp. 117-119, 1991.

[9] H. Kurita, M. Chino, K. Kurashina, and A. Kotani, "Phlebothrombosis with phlebolith of the tongue," Oral Surgery, Oral Medicine, Oral Pathology, vol. 77, no. 6, p. 552, 1994.

[10] H. Kato, Y. Ota, M. Sasaki, T. Arai, Y. Sekido, and K. Tsukinoki, "A phlebolith in the anterior portion of the masseter muscle," Tokai Journal of Experimental and Clinical Medicine, vol. 37, no. 1, pp. 25-29, 2012. 
[11] B. O'Riordan, "Phleboliths and salivary calculi," British Journal of Oral Surgery, vol. 12, no. 2, pp. 119-131, 1974.

[12] C. J. Keathley, R. L. Campbell, and J. W. Isbell, "Arteriovenous malformation and associated phleboliths. Report of a case," Oral Surgery, Oral Medicine, Oral Pathology, vol. 56, no. 2, pp. 132135, 1983.

[13] P. Scolozzi, F. Laurent, T. Lombardi, and M. Richter, "Intraoral venous malformation presenting with multiple phleboliths," Oral Surgery, Oral Medicine, Oral Pathology, Oral Radiology, and Endodontics, vol. 96, no. 2, pp. 197-200, 2003.

[14] M. Gunge, H. Yamamoto, T. Sakae, T. Katoh, and H. Izumi, "Venous hemangioma with phleboliths-a case study using immunohistochemistry, scanning electron microscopy and $\mathrm{x}$ ray microdiffraction," The Journal of Nihon University School of Dentistry, vol. 29, no. 3, pp. 211-220, 1987.

[15] T. M. Gharaibeh, R. A. Safadi, M. A. Rawashdeh, and H. M. Hammad, "Plunging arteriovenous malformation in the floor of the mouth: a case report," British Journal of Oral and Maxillofacial Surgery, vol. 48, no. 8, pp. e35-e37, 2010.

[16] N. Ikegami and K. Nishijima, "Hemangioma of the buccal pad with phlebolithiasis: report of a case," Acta Medica Okayama, vol. 38, no. 1, pp. 79-87, 1984.

[17] K. Sano, A. Ogawa, T. Inokuchi, H. Takahashi, and K. Hisatsune, "Buccal hemangioma with phleboliths. Report of two cases," Oral Surgery, Oral Medicine, Oral Pathology, vol. 65, no. 2, pp. 151-156, 1988.

[18] J. R. Hupp, "Facial phleboliths," Oral Surgery, Oral Medicine, Oral Pathology, vol. 67, no. 3, p. 361, 1989.

[19] H. Çankaya, Ö. Ünal, S. Ugras, K. Yuca, and M. Kiriş, "Hemangioma with phleboliths in the sublingual gland: as a cause of submental opacity," Tohoku Journal of Experimental Medicine, vol. 199, no. 3, pp. 187-191, 2003.

[20] Y.-X. Su, G.-Q. Liao, L. Wang, Y.-J. Liang, M. Chu, and G.-S. Zheng, "Sialoliths or phleboliths?" Laryngoscope, vol. 119, no. 7, pp. 1344-1347, 2009.

[21] H. J. Choi, J. C. Lee, J. H. Kim, Y. M. Lee, and H. J. Lee, "Cavernous hemangioma with large phlebolith of the parotid gland," The Journal of Craniofacial Surgery, vol. 24, no. 6, pp. e621-e623, 2013.

[22] A. G. Leyva, S. L. Maguid, M. A. R. de Benyacar, M. A. Lazaro, J. M. Cocco, and G. Citera, "Pathological mineralizations: calcifications and Si-bearing particles in soft tissues and their eventual relationship to different prostheses," Artificial Organs, vol. 24, no. 3, pp. 179-181, 2000.

[23] N. B. Matsko, N. Žnidaršič, I. Letofsky-Papst et al., "Silicon: the key element in early stages of biocalcification," Journal of Structural Biology, vol. 174, no. 1, pp. 180-186, 2011. 


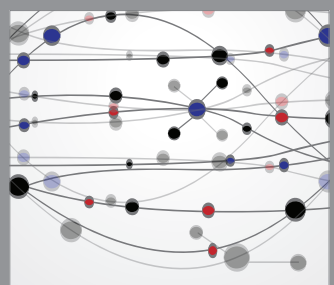

The Scientific World Journal
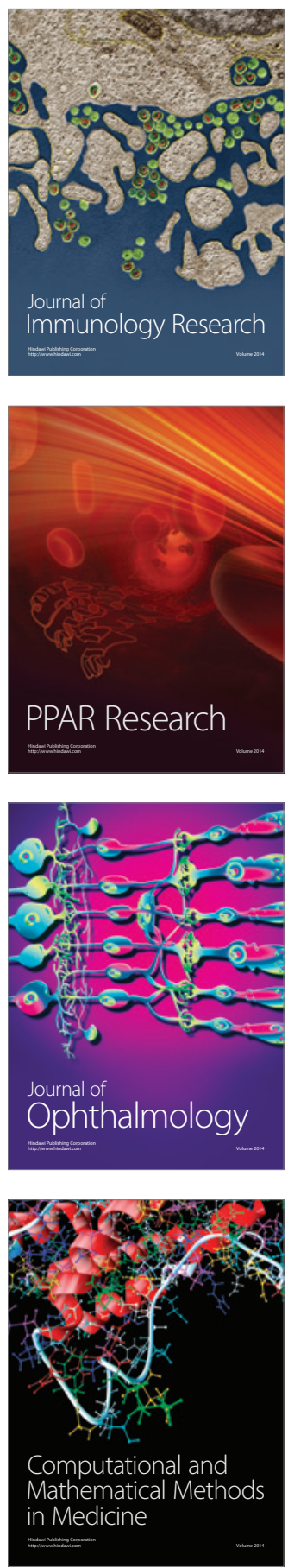

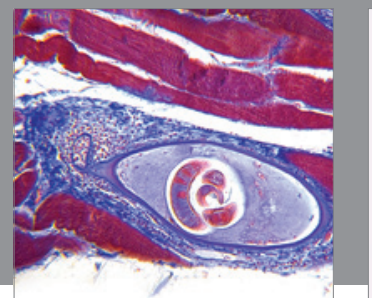

Gastroenterology

Research and Practice
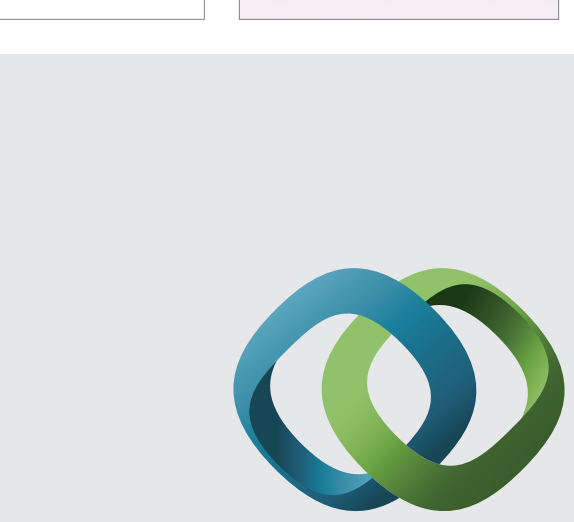

\section{Hindawi}

Submit your manuscripts at

http://www.hindawi.com
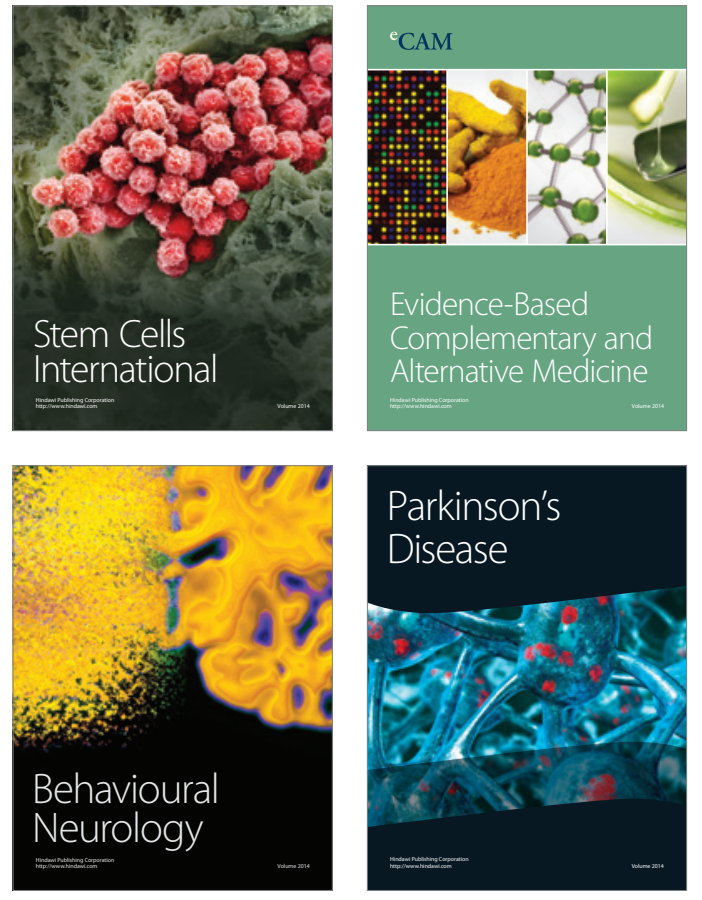
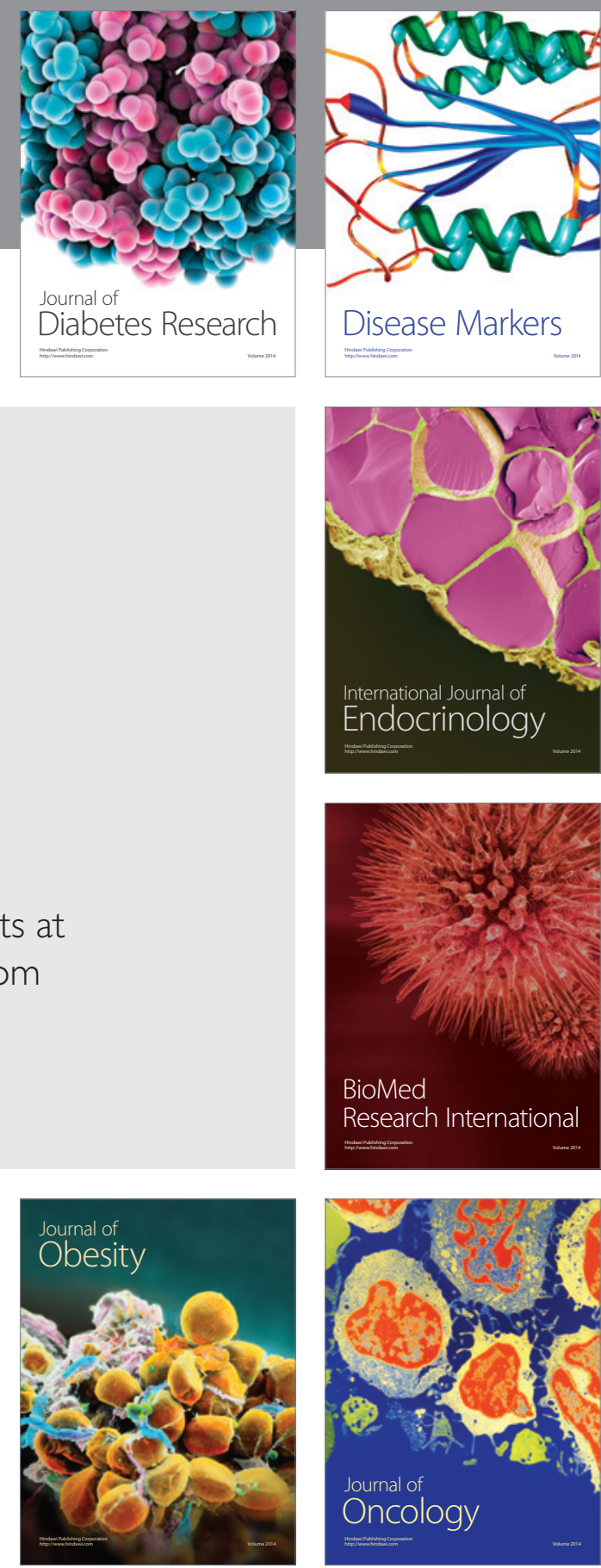

Disease Markers
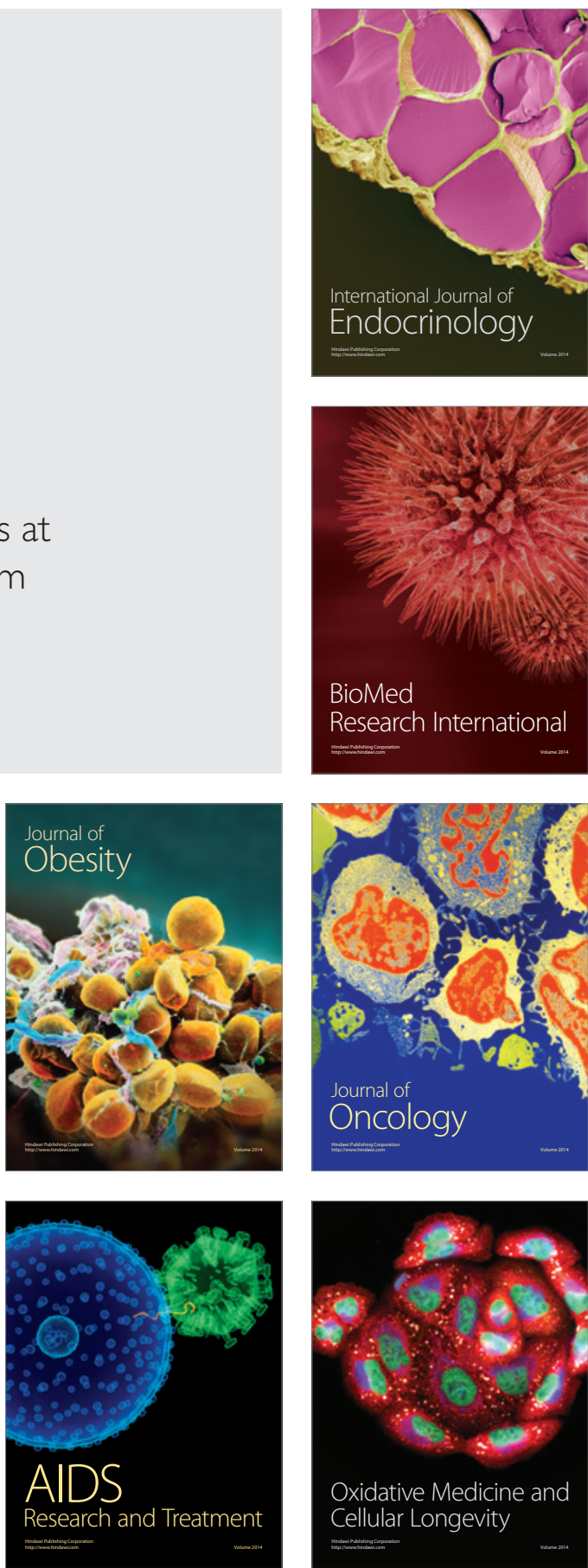